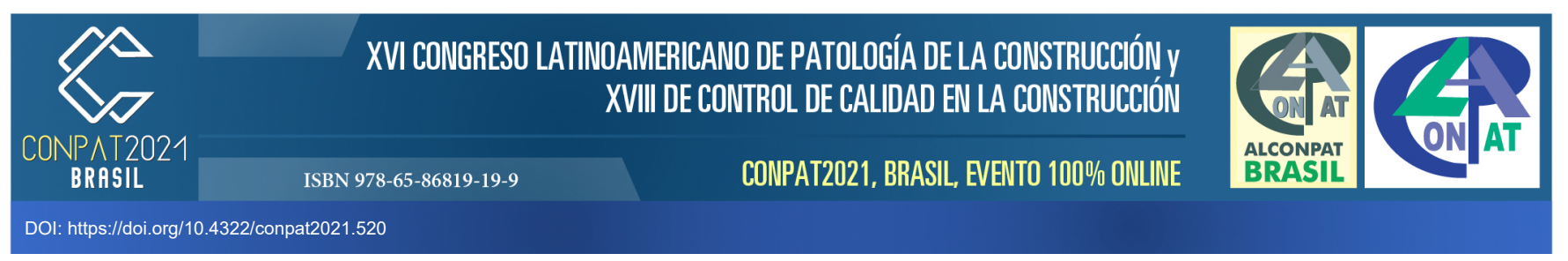

\title{
VERIFICAÇÃO DO EMPREGO DE ENDURECEDORES DE SUPERFÍCIE COMO ALTERNATIVA PARA RECUPERAÇÃO DE FACHADA COM SUPERFICIE PULVERULENTA
}

\author{
Francisco Gabriel Santos. Silva ${ }^{1}$, Marcus. Mendes ${ }^{2 *}$, Vinícius Almeida. Coelho ${ }^{3}$, A. R. A. \\ $\mathrm{OMORE}^{4}$ \\ *Autor de Contacto: marcus.mendes@ifg.edu.br
}

\begin{abstract}
${ }^{1}$ Prof. Adjunto do Departamento de Construção Civil e Estruturas, Escola Politécnica da UFBA, Salvador, Brasil
${ }^{2}$ Prof. do NUCCTEC, Curso Bacharelado em Engenharia Civil, Instituto Federal de Goiás, Goiânia, Brasil

${ }^{3}$ Doutorando do Programa de Pós-Graduação em Engenharia Civil, Escola Politécnica da UFBA, Salvador, Brasil

${ }^{4}$ Graduado em Engenharia Civil, Escola Politécnica da UFBA, Salvador, Brasil
\end{abstract}

\begin{abstract}
RESUMO
O sistema de revestimento é definido como um conjunto de subsistemas responsável por conferir funções como proteger à alvenaria, regularizar às superfícies, manter estanque e prezar por uma adequada estética as vedações. A ocorrência dessas manifestações patológicas de pulverulência nos revestimentos compromete o desempenho do sistema de revestimento, assim reduzindo a sua vida útil e capacidade de receber novas camadas e provocar manifestações patológicas de desplacamento cerâmico ou empolamento de pintura. Para tanto, o presente trabalho teve como objetivo principal avaliar a eficiência do endurecedor de superfície em fachada com pulverulência de superfície de um condomínio situado na cidade de Salvador-BA, na qual foi utilizado um produto comercial, realizando ensaio de resistência de aderência superficial antes e depois da aplicação. Os resultados mostraram que o endurecedor de superfície utilizado melhorou substancialmente as características mecânicas da superfície do emboço, eliminando a pulverulência superficial.
\end{abstract}

Palavras chave: Fachada; Manifestações patológicas; Endurecedor de superfície.

\begin{abstract}
Facades, as the most external elements of a building, are characterized as the construction system most exposed to adverse conditions and aggressive agents, therefore, the most susceptible to the action of harmful phenomena. The present study sought to analyze the pathological manifestations acting in a façade system with a stone coating finish in a building in the city of Salvador - BA. After identifying the affected regions and diagnosing the possible causes of the pathologies, alternative treatment options were proposed to correct the problems, including the fixation of the ornamental rocks with stainless steel screws. The results observed highlight the importance of preventive maintenance to guarantee the performance of coatings, with the absence of maintenance for 37 years being the main cause of the identified problems.

Keywords: Maintenance; facades; stone coating; recovery.
\end{abstract}

\section{RESUMEN}


El sistema de revestimiento se define como un conjunto de subsistemas encargados de brindar funciones como proteger la mampostería, alisar las superficies, mantenerla estanca y dotar a las vallas de una estética adecuada. La ocurrencia de estas manifestaciones patológicas en los recubrimientos compromete el desempeño del sistema de recubrimiento, reduciendo así su vida útil. Por tanto, existen metodologías consolidadas que abordan la comprensión del problema de la degradación de los revestimientos de fachadas, por ejemplo. Así como existen metodologías para cuantificar la degradación y estimar la vida útil. Para ello, el presente trabajo tuvo como objetivo principal evaluar la eficiencia del endurecedor superficial en fachadas de un condominio ubicado en la ciudad de Salvador-BA / Brasil. Finalmente, se constató que esta medida correctiva resultó ser eficaz.

Palabras llave: Fachada; Manifestaciones patológicas; Endurecedor de superficies.

\section{INTRODUÇÃO}

O sistema de revestimento é definido como um conjunto de subsistemas responsável por conferir funções como proteger à alvenaria, regularizar às superfícies, manter estanque e prezar por uma adequada estética as vedações. Essas funções dependem de uma eficiente aderência argamassasubstrato, da qualidade dos materiais empregados e de ajustes conforme às características de projeto do edifício. Estes requisitos não atendidos, podem propiciar o surgimento de manifestações patológicas no sistema de revestimento, tais como, descolamento de cerâmica, desplacamento de cerâmica, fissuração, eflorescência, pulverulência, descascamento da pintura e falha de vedação. A ocorrência dessas manifestações patológicas nos revestimentos compromete o desempenho do sistema de revestimento, assim reduzindo a sua vida útil. Para tanto, Silva (2014) afirma que é necessário efetuar estudos e conhecer bem o comportamento de diversas variantes que condicionam o surgimento e a evolução das manifestações patológicas, por exemplo em fachadas de edifícios, a fim de propor medidas de prevenção e de correção dos danos que as comprometem.

Paes e Carasek (2007) alertam para a necessidade do entendimento das causas e mecanismos dos eventuais fenômenos patológicos atuantes em virtude, principalmente, das diferentes características dos materiais utilizados e das condições de exposição. Isto requer suficiente conhecimento científico e tecnológico do conjunto, fazendo-se necessários estudos e pesquisas em torno desses fenômenos. Nesse sentido, há pesquisas realizadas que auxiliam no entendimento da problemática da degradação em fachadas com emprego de metodologias (Flores-Colen e Brito, 2010; Gaspar e Brito, 2008). Há também pesquisas que buscam estabelecer métodos de quantificação da degradação e estimativa da vida útil (Gaspar e Brito, 2008; Silva, A et al, 2014; Souza, 2019).

Com base nas pesquisas e metodologias citadas acima, o presente trabalho teve como objetivo principal avaliar a eficiência do endurecedor de superfície em fachadas de um condomínio situado na cidade de Salvador-BA/ Brasil. Além disso, diagnosticar a situação real do sistema do sistema emboço/reboco, da camada de regularização já feita e da pintura, a fim de se avaliar a necessidade da remoção de toda a tinta ou a manutenção da primeira camada de pintura, removendo as demais.

\section{METODOLOGIA}

\subsection{Objeto de estudo}

O objeto de estudo trata-se de uma edificação que está localizada em um condomínio na cidade de Salvador - BA/Brasil, constituída de duas torres (A e B) de 12 pavimentos, as quais possuem fachadas com revestimento misto de acabamento cerâmico e pintura. A seguir, estão descritas 
informações de laudos técnicos, em ordem cronológica, de inspeções realizadas nas fachadas deste edifício anteriormente ao presente estudo. Essas informações foram importantes para o desenvolvimento do atual trabalho.

O primeiro laudo, emitido por uma empresa especializada, relata que foi identificado a ocorrência de fissuração e desplacamento de pastilhas na fachada. Identificou-se a presença de arenoso na constituição do reboco, bem como foi constatado em ensaios de resistência de aderência à tração resultados médios de $0,19 \mathrm{MPa}$ para a Torre A e $0,24 \mathrm{Mpa}$ para a Torre B com formas de rupturas predominantemente dos tipos C e D.

O segundo laudo, emitido pela por uma segunda empresa especializada, consta que foram realizados um estudo de som cavo e um ensaio de resistência de aderência à tração em desconformidade com a NBR 13749 no que tange à quantidade de corpos de prova (adotou-se dois cp's por pavimento e a média aritmética dos seus resultados, enquanto a norma exige 12 corpos de prova). Constatou-se som cavos e espessuras de até $70 \mathrm{~mm}$ do sistema emboço/reboco sem estruturação. Como conclusão foi recomendado a execução de juntas de movimentação e dessolidarização, estruturação no fundo de vigas com resina epoxídica e argamassa tixotrópica, recuperação de fissuras com massa acrílica e estruturação da pintura com tela de poliéster.

Por fim, constam relatórios de ensaios de aderência na fachada Norte realizados pelo Centro Tecnológico da Argamassa (CETA/UFBA) na fachada norte, nos quais foram obtidos resultados de aderência médios de $0,18 \mathrm{MPa}$ (com ruptura predominante tipo E (interface emboço/argamassa de regularização), 0,24MPa (com ruptura predominante tipo E (interface emboço/argamassa de regularização) e $0,22 \mathrm{MPa}$ (com ruptura predominante tipo $\mathrm{E}$ (interface emboço/argamassa de regularização), respectivamente. Observa-se que os resultados não atenderam as recomendações da NBR 13749.

\subsection{Procedimento de investigação e análise}

Após a análise de toda a documentação técnica produzida e de inspeções in loco, é importante ressaltar que foi identificado a presença do arenoso na constituição do sistema emboço/reboco, que provocou pulverulência e fissuração no revestimento, evidenciando que não foi realizado um estudo de dosagem adequado do revestimento. Foram encontradas espessuras acima do recomendado por norma $(30 \mathrm{~mm})$ sem a devida estruturação solicitada pela NBR 7200, além disso, o valor dos ensaios de resistência de aderência à tração foram abaixo do especificado pela NBR 13749 ( 8 corpos de prova com valores acima de $0,30 \mathrm{MPa}$ ) e com ruptura predominantemente tipo E (interior do reboco).

Ainda que pese o fato de a aderência estar abaixo do valor normativo, isso não é motivo suficiente para a condenação do sistema de revestimento, pois os mecanismos de aderência do sistema estão envolvidos por outros fatores intervenientes, tais como, aderência superficial, módulo de elasticidade e coesão do sistema.

Diante disso, decidiu-se estudar diferentes cenários para se avaliar o melhor mecanismo de tratamento do sistema emboço/reboco, a fim de propor a recuperação da fachada de forma a atender aos critérios técnicos e econômicos;

a) Cenário 1: Resistencia de aderência superficial na camada de revestimento do sistema emboço/reboco sem tratamento no Playground da Torre A;

b) Cenário 2: Resistencia de aderência superficial na camada de revestimento do sistema emboço/reboco com tratamento feito utilizando Endurecedor de superfície (com duas demãos) no Playground da Torre A;

c) Cenário 3: Resistencia de aderência superficial na camada de regularização do revestimento do sistema emboço/reboco feita pela construtora; 
d) Cenário 4: Resistencia de aderência superficial na primeira camada de pintura do sistema emboço/reboco sem tratamento.

Cabe destacar, que a norma NBR 13755 exige a amostragem de 12 corpos de prova (CP's) a cada $2000 \mathrm{~m} 2$, devendo ser aprovado os resultados que apresentem mínimo de $8 \mathrm{CP}$ 's acima de 0,50MPa, e devendo consultar o projetista de a resistência ficar entre 0,3 e 0,5MPa para os $8 \mathrm{CP}^{\prime} \mathrm{s}$.

\section{RESULTADOS E DISCUSSÃO}

\section{a) Cenário 1: Resistencia de aderência superficial na camada de revestimento do sistema emboço/reboco sem tratamento no Playground da Torre A.}

Os resultados apresentaram uma resistência média de $0,46 \mathrm{MPa}$, com $06 \mathrm{CP}^{\prime}$ s entre $0,3 \mathrm{MPa}$ e $0,5 \mathrm{MPa}$ e $05 \mathrm{CP}^{\prime}$ s com valores acima de $0,5 \mathrm{Mpa}$, conforme se observa na Tabela 1 . O formato de ruptura foi 100\% tipo B (superfície do reboco com partes da argamassa arrancadas), conforme se verifica na Figura 1. Esses valores não apresentam um desvio de resultados que comprometessem o sistema de revestimento, mas o fato de haver presença de arenoso e muita pulverulência, não é recomendado a manutenção dessa camada de revestimento sem o devido tratamento superficial.

Tabela 1. Resistência de aderência superficial na camada de revestimento do sistema emboço/reboco sem tratamento no Playground da Torre A

\begin{tabular}{|c|c|c|c|c|c|c|c|c|}
\hline \multirow[b]{2}{*}{$\mathbf{C P}$} & \multirow{2}{*}{$\begin{array}{c}\text { Diâmetro } \\
\text { (mm) }\end{array}$} & \multirow{2}{*}{$\begin{array}{l}\text { Area da } \\
\text { seção } \\
\left(\mathbf{m m}^{2}\right)\end{array}$} & \multirow{2}{*}{$\begin{array}{c}\text { Carga de } \\
\text { ruptura }(\mathbf{N})\end{array}$} & \multirow{2}{*}{$\begin{array}{c}\text { Resistência de } \\
\text { aderência } \\
\text { superficial } \\
\text { (MPa) }\end{array}$} & \multicolumn{4}{|c|}{ Forma de Ruptura (\%) } \\
\hline & & & & & $\mathbf{a}$ & $\mathbf{b}$ & $\mathrm{C}$ & d \\
\hline 01 & 50,0 & 1964 & 1150 & 0,58 & - & 100 & - & - \\
\hline 02 & 50,0 & 1964 & 1100 & 0,56 & - & 100 & - & \\
\hline $\mathbf{0 3}$ & 50,0 & 1964 & 650 & 0,33 & - & 100 & - & - \\
\hline 04 & 50,0 & 1964 & 550 & 0,28 & - & 100 & - & - \\
\hline 05 & 50,0 & 1964 & 950 & 0,48 & - & 100 & - & - \\
\hline 06 & 50,0 & 1964 & 1200 & 0,61 & - & 100 & - & - \\
\hline 07 & 50,0 & 1964 & 850 & 0,43 & - & 100 & - & - \\
\hline 08 & 50,0 & 1964 & 650 & 0,33 & - & 100 & - & - \\
\hline 09 & 50,0 & 1964 & 1000 & 0,51 & - & 100 & - & - \\
\hline 10 & 50,0 & 1964 & 1100 & 0,56 & - & 100 & - & - \\
\hline 11 & 50,0 & 1964 & 900 & 0,46 & - & 100 & - & - \\
\hline 12 & 50,0 & 1964 & 850 & 0,43 & - & 100 & - & - \\
\hline
\end{tabular}

Forma de Ruptura:

a) Ruptura no interior do reboco.

b) Ruptura da superfície do reboco, onde partes da argamassa são arrancadas;

c) Ruptura na interface cola/substrata, quando apenas poucos grãos são arrancados;

d) Ruptura na interface pastilha metálica/cola. 


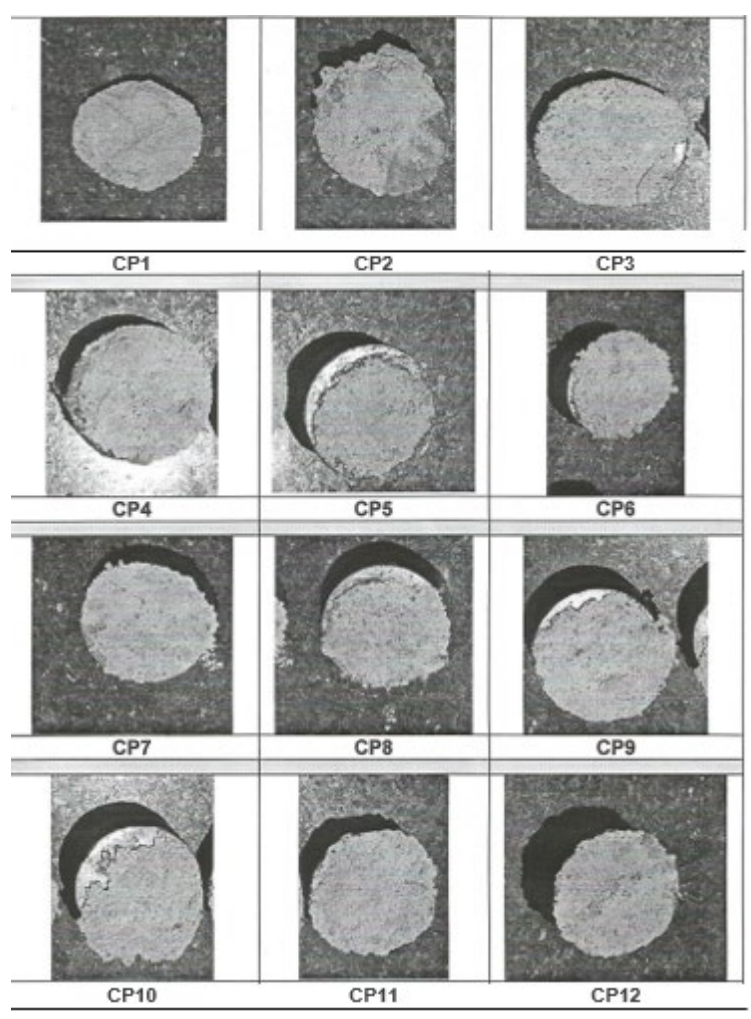

Figura 1. Formato de ruptura dos CP's do cenário 1.

b) Cenário 2: Resistência de aderência superficial na camada de revestimento do sistema emboço/reboco com tratamento feito utilizando Endurecedor de superfície (com duas demãos) no Playground da Torre A.

Os resultados apresentaram uma resistência média de 1,41MPa, com todos os $\mathrm{CP}$ 's com valores acima de $0,5 \mathrm{MPa}$, conforme se observa na Tabela 2 . O formato de ruptura foi $100 \%$ tipo A (interior do reboco) conforme se observa na Figura 2. Isso significa, que a utilização do tratamento superficial do sistema emboço/reboco com o endurecedor de superfície se mostrou eficiente. 
Tabela 2. Resistência de aderência superficial na camada de revestimento do sistema emboço/reboco com tratamento feito utilizando endurecedor de superfície (com duas demãos).

\begin{tabular}{|c|c|c|c|c|c|c|c|c|}
\hline \multirow[b]{2}{*}{ CP } & \multirow{2}{*}{$\begin{array}{c}\text { Diâmetro } \\
(\mathbf{m m})\end{array}$} & \multirow{2}{*}{$\begin{array}{c}\text { Área da } \\
\text { seção } \\
\left(\mathrm{mm}^{2}\right)\end{array}$} & \multirow{2}{*}{$\begin{array}{l}\text { Carga de } \\
\text { ruptura (N) }\end{array}$} & \multirow{2}{*}{$\begin{array}{l}\text { Resistência de } \\
\text { aderência } \\
\text { superficial } \\
\text { (MPa) }\end{array}$} & \multicolumn{4}{|c|}{ Forma de Ruptura (\%) } \\
\hline & & & & & a & b & C & d \\
\hline 01 & 50,0 & 1964 & 2450 & 1,25 & 100 & - & - & - \\
\hline 02 & 50,0 & 1964 & 2000 & 1,02 & 100 & - & - & \\
\hline 03 & 50,0 & 1964 & 2650 & 1,34 & 100 & - & - & - \\
\hline 04 & 50,0 & 1964 & 4200 & 2,14 & 100 & - & - & - \\
\hline 05 & 50,0 & 1964 & 3000 & 1,53 & 100 & - & - & - \\
\hline 06 & 50,0 & 1964 & 2450 & 1,25 & 100 & - & - & - \\
\hline 07 & 50,0 & 1964 & 3200 & 1,63 & 100 & - & - & - \\
\hline 08 & 50,0 & 1964 & 2100 & 1,07 & 100 & - & - & - \\
\hline 09 & 50,0 & 1964 & 2800 & 1,43 & 100 & - & - & - \\
\hline 10 & 50,0 & 1964 & 2650 & 1,35 & 100 & - & - & - \\
\hline 11 & 50,0 & 1964 & 2850 & 1,45 & 100 & - & - & - \\
\hline 12 & 50,0 & 1964 & 2800 & 1,43 & 100 & - & - & - \\
\hline
\end{tabular}

Forma de Ruptura:

a) Ruptura no interior do reboco.

b) Ruptura da superfície do reboco, onde partes da argamassa são arrancadas;

c) Ruptura na interface cola/substrata, quando apenas poucos grãos são arrancados;

d) Ruptura na interface pastilha metálica/cola.

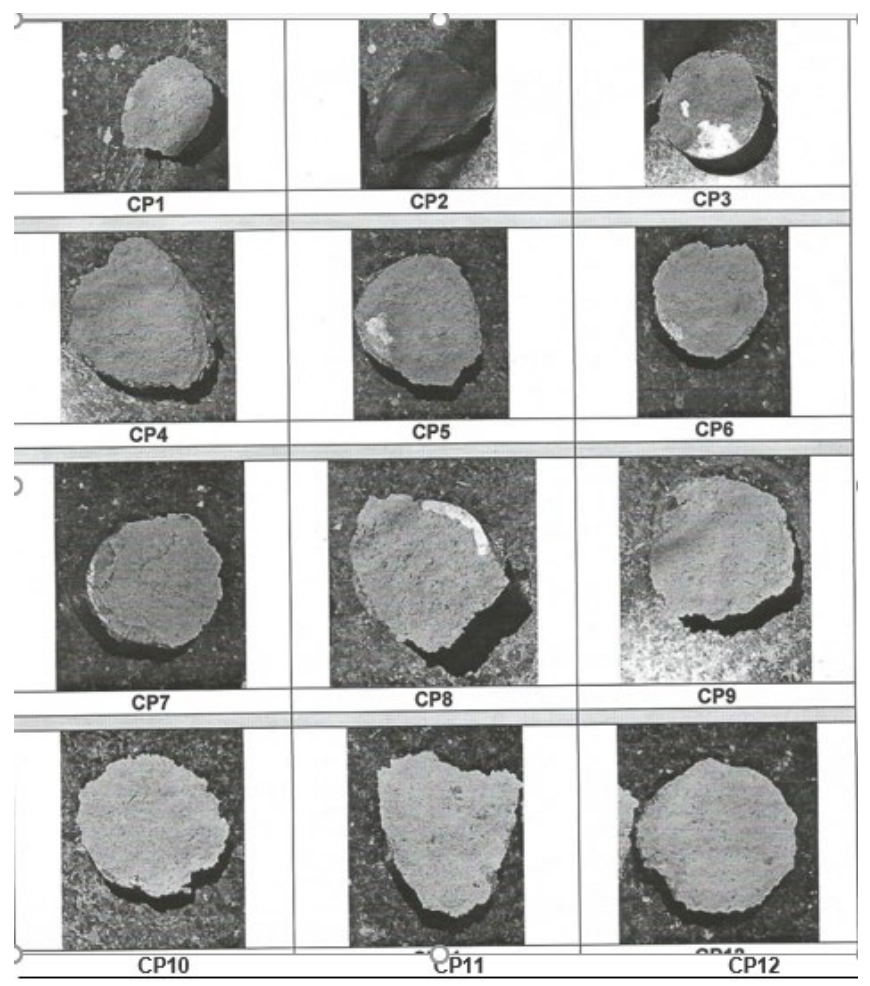

Figura 2. Formato de ruptura dos CP's do cenário 2.

c) Cenário 3: Resistencia de aderência superficial na camada de regularização do revestimento do sistema emboço/reboco feita pela construtora

Os resultados apresentaram uma resistência média de $0,29 \mathrm{MPa}$, com $06 \mathrm{CP}^{\prime}$ s entre $0,3 \mathrm{MPa}$ e 0,5 $\mathrm{MPa}$ e ao demais $\mathrm{CP}^{\prime}$ s com valores abaixo de $0,3 \mathrm{Mpa}$, conforme se observa na Tabela 3 . O 
formato de ruptura foram tipos A, B e C (argamassa de regularização/reboco, interior da argamassa de reboco e interior da argamassa de regularização), conforme se observa na Figura 3. Isso significa, que a aplicação da camada de regularização sem o devido tratamento de superficial no sistema emboço/reboco não atendeu aos critérios normativos, devendo toda a camada realizada ser removida para a realização de tratamento de superfície com endurecedor.

Tabela 3. Resistência de aderência superficial na camada de regularização do revestimento do sistema emboço/reboco feita

\begin{tabular}{|c|c|c|c|c|c|c|c|c|}
\hline \multirow[b]{2}{*}{ CP } & \multirow{2}{*}{$\begin{array}{l}\text { Diâmetro } \\
(\mathrm{mm})\end{array}$} & \multirow{2}{*}{$\begin{array}{c}\text { Área da } \\
\text { seção } \\
\left(\mathrm{mm}^{2}\right)\end{array}$} & \multirow{2}{*}{$\begin{array}{c}\text { Carga de } \\
\text { ruptura (N) }\end{array}$} & \multirow{2}{*}{$\begin{array}{l}\text { Resistência de } \\
\text { aderência } \\
\text { superficial } \\
\text { (MPa) }\end{array}$} & \multicolumn{4}{|c|}{ Forma de Ruptura (\%) } \\
\hline & & & & & $\mathbf{a}$ & $\mathrm{b}$ & c & d \\
\hline 01 & 50,0 & 1964 & 400 & 0,20 & 20 & 80 & - & - \\
\hline 02 & 50,0 & 1964 & 650 & 0,33 & 60 & 40 & - & \\
\hline 03 & 50,0 & 1964 & 600 & 0,31 & 70 & 30 & - & - \\
\hline 04 & 50,0 & 1964 & 650 & 0,33 & - & 60 & 40 & - \\
\hline 05 & 50,0 & 1964 & 800 & 0,41 & 5 & - & 95 & - \\
\hline 06 & 50,0 & 1964 & 550 & 0,28 & 5 & - & 95 & - \\
\hline 07 & 50,0 & 1964 & 600 & 0,31 & 30 & - & 70 & - \\
\hline 08 & 50,0 & 1964 & 800 & 0,41 & - & 70 & 30 & - \\
\hline 09 & 50,0 & 1964 & 450 & 0,23 & - & 60 & 30 & - \\
\hline 10 & 50,0 & 1964 & 500 & 0,25 & 65 & - & 35 & - \\
\hline 11 & 50,0 & 1964 & 550 & 0,28 & - & 10 & 90 & - \\
\hline 12 & 50,0 & 1964 & 350 & 0,18 & 45 & 55 & - & - \\
\hline
\end{tabular}

Forma de Ruptura:

a) Ruptura no interior do reboco.

b) Ruptura da superfície do reboco, onde partes da argamassa são arrancadas;

c) Ruptura na interface cola/substrata, quando apenas poucos grãos são arrancados;

d) Ruptura na interface pastilha metálica/cola. 


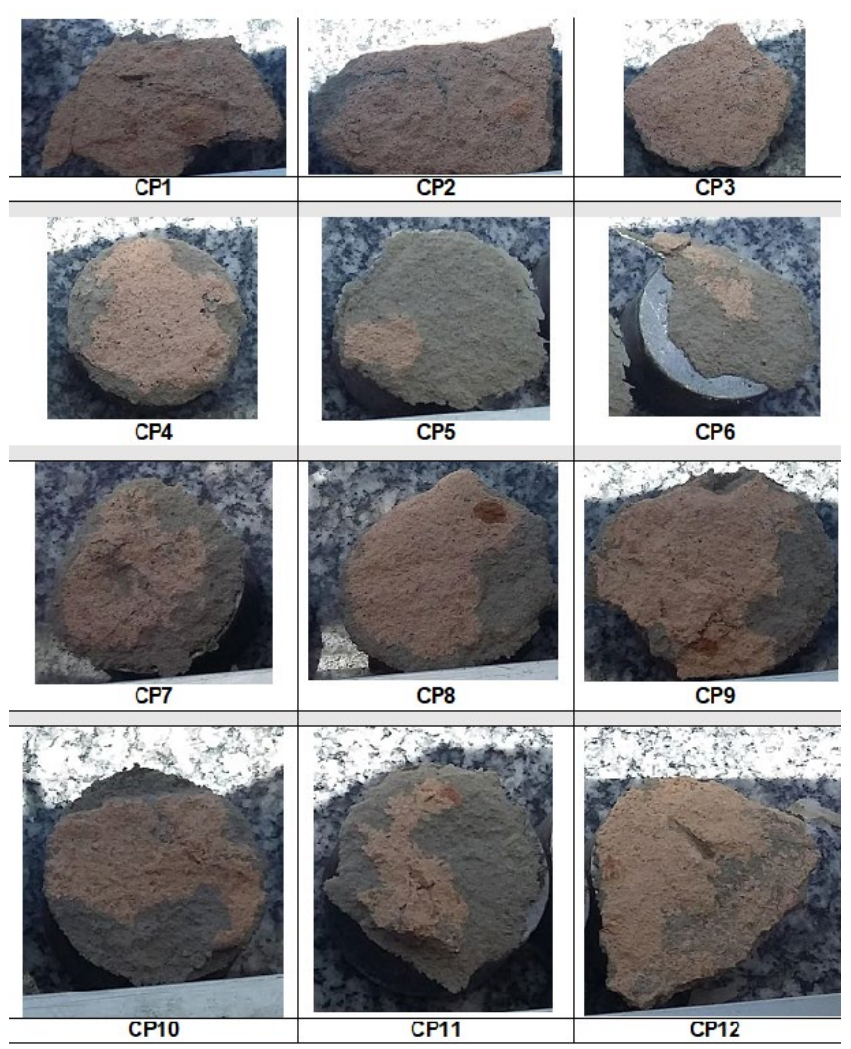

Figura 3. Formato de ruptura dos CP's do cenário 3.

\section{d) Cenário 4: Resistencia de aderência superficial na primeira camada de pintura do sistema emboço/reboco sem tratamento}

Os resultados apresentaram uma resistência média de $0,60 \mathrm{MPa}$, com $04 \mathrm{CP}^{\prime}$ s entre $0,3 \mathrm{MPa}$ e $0,5 \mathrm{MPa}$ e os demais $\mathrm{CP}^{\prime} \mathrm{s}$ com valores acima de $0,5 \mathrm{Mpa}$, conforme se observa na Tabela 4 . O formato de ruptura foram tipos A e B (argamassa de regularização/reboco, interface massa corrida/reboco) conforme se observa na Figura 4. Esses resultados mostram que a primeira camada de pintura está bem aderida à superfície do sistema emboço/reboco, se tornando além de uma camada aglomerante, protetora diante das possíveis fissuras existentes no fundo e não aparentes na superfície, pois a sua elasticidade permite uma movimentação da fissura sem prejuízos na camada de tinta. 
Tabela 4. Resistência de aderência superficial na primeira camada de pintura do sistema emboço/reboco sem tratamento

\begin{tabular}{|c|c|c|c|c|c|c|c|c|}
\hline \multirow[b]{2}{*}{ CP } & \multirow{2}{*}{$\begin{array}{l}\text { Diâmetro } \\
(\mathbf{m m})\end{array}$} & \multirow{2}{*}{$\begin{array}{c}\text { Área da } \\
\text { seção } \\
\left(\mathrm{mm}^{2}\right)\end{array}$} & \multirow{2}{*}{$\begin{array}{l}\text { Carga de } \\
\text { ruptura (N) }\end{array}$} & \multirow{2}{*}{$\begin{array}{l}\text { Resistencia de } \\
\text { aderência } \\
\text { superficial } \\
\text { (MPa) }\end{array}$} & \multicolumn{4}{|c|}{ Forma de Ruptura (\%) } \\
\hline & & & & & a & b & C & d \\
\hline 01 & 50,0 & 1964 & 850 & 0,43 & 100 & - & - & - \\
\hline 02 & 50,0 & 1964 & 750 & 0,38 & 100 & - & - & \\
\hline 03 & 50,0 & 1964 & 1250 & 0,64 & 30 & 70 & - & - \\
\hline 04 & 50,0 & 1964 & 1100 & 0,56 & 70 & 30 & - & - \\
\hline 05 & 50,0 & 1964 & 800 & 0,41 & 100 & - & - & - \\
\hline 06 & 50,0 & 1964 & 1350 & 0,68 & 100 & - & - & - \\
\hline 07 & 50,0 & 1964 & 950 & 0,48 & - & 100 & - & - \\
\hline 08 & 50,0 & 1964 & 2000 & 1,02 & - & 100 & - & - \\
\hline 09 & 50,0 & 1964 & 1400 & 0,71 & 30 & 70 & - & - \\
\hline 10 & 50,0 & 1964 & 1050 & 0,53 & 100 & - & - & - \\
\hline 11 & 50,0 & 1964 & 1200 & 0,61 & 30 & 70 & - & - \\
\hline 12 & 50,0 & 1964 & 1550 & 0,79 & 40 & 70 & - & - \\
\hline
\end{tabular}

Forma de Ruptura:

a) Ruptura no interior do reboco.

b) Ruptura da superfície do reboco, onde partes da argamassa são arrancadas;

c) Ruptura na interface cola/substrata, quando apenas poucos grãos são arrancados;

d) Ruptura na interface pastilha metálica/cola.

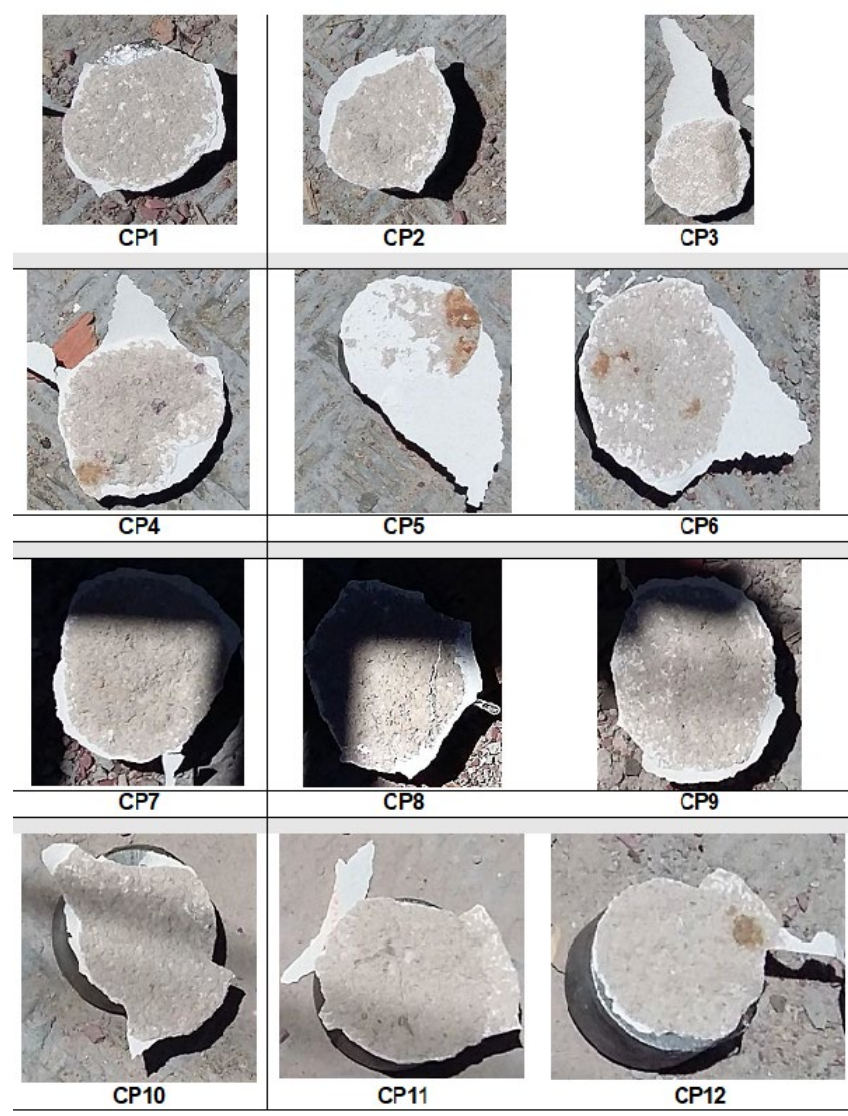

Figura 4. Formato de ruptura dos CP's do cenário 4. 


\section{CONCLUSÃO}

Diante das análises dos documentos técnicos produzidos anteriormente e dos resultados obtidos na presente pesquisa, pode-se destacar as seguintes conclusões:

- A utilização do tratamento superficial do sistema emboço/reboco com o endurecedor de superfície se mostrou eficiente.

- Recomenda-se a manutenção da primeira camada de pintura, removendo todas as camadas posteriores, além da realização do tratamento de fissura nos locais identificados;

- Recomenda-se a remoção de toda a camada de regularização realizada, pois a mesma se mostrou ineficiente na avaliação do ensaio de aderência superficial;

- Recomenda-se a aplicação do endurecedor de superfície em toda a área da fachada a ser pastilhada, inclusive nas juntas, seguindo as recomendações do fabricante quanto ao número de demãos e intervalo entre as mesmas. Salienta-se que todas as esquadrias devem ser protegidas dos respingos do produto que não tem remoção fácil.

\section{REFERENCIAS}

ABNT - Associação Brasileira de Normas Técnicas. (2019). NBR 13528-1: Revestimentos de Paredes e Tetos de Argamassas Inorgânicas- Determinação da Resistência de Aderência à TraçãoRequisitos Gerais. Rio de Janeiro.

ABNT - Associação Brasileira de Normas Técnicas. (1998). NBR 7200: Execução de Revestimento de Paredes e Tetos de Argamassas Inorgânicas - Procedimento. Rio de Janeiro.

ABNT - Associação Brasileira de Normas Técnicas. (2017). NBR 13755: Revestimentos Cerâmicos de Fachadas e Paredes Externas com Utilização de Argamassa Colante. Rio de Janeiro.

ABNT - Associação Brasileira de Normas Técnicas. (2013). NBR 13749: Revestimentos de Paredes e Tetos de Argamassas Inorgânicas - Especificação. Rio de Janeiro.

Carasek, H. "Patologia das argamassas de revestimento. Materiais de Construção e Princípios de Ciência e Engenharia de Materiais”. IBRACON, São Paulo, v. 1, 2007, p. 1-11.

Gaspar, P.; Brito, J (2008). Quantifying environmental effects on cement-rendered facades: a comparison between different degradation indicators. Building and Environment, v. 43, n. 11, p. 1818-28.

Silva, M. N. B. (2014). "Avaliação Quantitativa da Degradação e Vida Útil de Revestimentos de Fachada - Aplicação ao Caso de Brasília/DF”. Tese de Doutorado em Estruturas e Construção Civil, Publicação E.TD-006A/14, Departamento de Engenharia Civil e Ambiental, Universidade de Brasília, Brasília, DF, 198 p.

Silva, A; Gaspar, P. L.; Brito, J. "Stochastic, deterministic, statistical and artificial intelligence based models to predict the service life of rendered facades", XIII International Conference on Durability of Building Materials and Components, XIII DBMC, São Paulo, Brasil, 2014. 
Souza, J. S. (2019). "Impacto dos fatores de degradação sobre a vida útil de fachadas de edificios". Tese de doutorado em Estruturas e Construção Civil, Publicação E.DT-15A/19, Departamento de Engenharia Civil e Ambiental, Universidade de Brasília, Brasília, DF, 139 p.

Flores-Colen, I.; Brito, J (2010). "A systematic approach for maintenance budgeting of buildings façades based on predictive and preventive strategies". Construction and Building Materials, v. 24, n. 9, p. 1718-1729. https://doi.org/10.1016/j.conbuildmat.2010.02.017 